Revista del Centro de Investigación de la Universidad La Salle

Vol. 13, No. 50, julio-diciembre, 2018: 47-68

DOI : http://dx.doi.org/10.26457/recein.v13i50.1754

\title{
Realidad virtual para dar a conocer los atractivos turísticos de \\ Tepeapulco, Hidalgo
}

\section{Virtual reality to publicize the tourist attractions of Tepeapulco, Hidalgo}

\author{
Yair Félix Olvera Mejía ${ }^{1}$ \\ Universidad La Salle Pachuca (México)/Universidad Politécnica \\ Metropolitana de Hidalgo (México) \\ Mario Alberto Gea Pérez \\ Universidad Politécnica Metropolitana de Hidalgo (México) \\ Marco Antonio González Silva \\ Universidad Politécnica Metropolitana de Hidalgo (México)
}

Recibido: 16 de octubre de 2018

Aceptado: 08 de abril de 2019

Publicado: 19 de junio de 2019

\section{Resumen}

En el presente texto se desarrolla una aplicación basada en realidad virtual para promocionar los atractivos turísticos del municipio de Tepeapulco en el estado de Hidalgo. El propósito es que las personas conozcan el lugar realizando un recorrido virtual a través de su teléfono celular, ya que en un futuro la Presidencia Municipal planea proponerlo como Pueblo

${ }^{1}$ Email: yfolvera@lasallep.mx

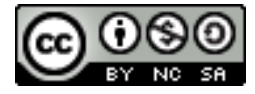

Revista del Centro de Investigación. Universidad La Salle por Dirección de Posgrado e Investigación. Universidad La Salle Ciudad de México se distribuye bajo una Licencia Creative Commons Atribución-NoComercial-Compartirlgual 4.0 
Olvera Mejía, Y.; Gea Pérez, M.; González Silva, M.

Mágico. Se describen todas las etapas para la creación de los escenarios virtuales, así como las etapas para realizar la aplicación en realidad virtual. Al mostrar la versión Beta de la aplicación a turistas que se encontraban en el centro de la población, se mostraron asombrados con la majestuosidad y esplendor de los lugares, ya que en Internet solo habían leído y visto algunas fotos de que visitar, pero no conocían a detalle cada uno de los atractivos. Con ello se fomenta el uso de nuevos medios innovadores para dar a conocer los lugares turísticos de una región y se incentiva a los turistas a visitarlos.

Palabras clave: Escenarios virtuales; Modelado 3D; Realidad virtual; Tepeapulco; Turismo. 


\section{Abstract}

This article describes how an application based on virtual reality was developed to promote the tourist attractions of the municipality of Tepeapulco in the state of Hidalgo. The purpose was for people to know the town through a virtual tour in their cell phones, as in the future the Municipal Presidency plans to propose it as a Magic Town. All the stages for the creation of virtual scenarios are described, as well as the stages to perform the application in Virtual Reality. When showing the Beta version of the application to tourists who were in the downtown area, they were amazed with the majesty and splendor of the places, because on the Internet they had only read and seen some photos of places to visit, but they did not know to detail each of the attractions. This encourages the use of new innovative means to publicize the tourist attractions of a region and encourages tourists to visit them.

Keywords: Virtual scenarios; 3D modeling; Virtual reality; Tepeapulco; Tourism. 


\section{Introducción}

El uso de las Tecnologías de la Información y la Comunicación (TIC) ha tenido un fuerte impacto en la sociedad actual, llegando a cubrir todos los ámbitos de la vida cotidiana, e incluso cambiando los mecanismos de acceso, desarrollo y difusión de la información. El turismo no se queda atrás en ese aspecto, y poco a poco han ido apareciendo programas tecnológicos para incentivar el entretenimiento y exploración de lugares mediante diversos medios de comunicación. Teniendo gran importancia ya que el fomento del turismo en el mercado tiene un valor concreto en términos del desarrollo económico de la localidad, además de ser un identificativo de la misma.

Estos avances tecnológicos han propiciado nuevas formas de realizar turismo, de tal manera que produzca en los individuos sensaciones iguales o similares a la realidad, es decir, generar experiencias únicas sin importar si éstas provienen de la realidad o la imaginación, de lo cual surge el concepto de post-turismo o también llamado turismo virtual. Su característica principal es generar en las personas experiencias turísticas sin necesidad de un desplazamiento físico a los lugares visitados (Molina, 2003; Ghisi \& Macedo, 2006; Chamorro, 2008). Otra forma de denominar al turismo virtual es cyberturismo, el cual describe que el usuario puede generar experiencias electrónicas de viajes simulados como sustituto de una experiencia física de turismo (Prideaux, 2005).

Sea cual sea el termino, la idea es generar nuevas formas de turismo aplicando tecnologías innovadoras como la realidad virtual, la cual a través de la simulación tridimensional interactiva por computadora permite que el usuario se sienta introducido en un ambiente artificial, generado a partir de datos existentes o imaginarios. De esta forma lo puede percibir como real, basado en estímulos de los órganos sensoriales como la vista y el oído (Burdea \& Coiffet, 1994; Martínez, 2011). El uso de esta tecnología permite recrear escenas basadas en información y datos turísticos, capaces de traspasar las barreras del tiempo, espacio y comunicación, promoviendo las posibilidades turísticas de un lugar. Sin embargo, las experiencias generadas desde la realidad virtual en el contexto del turismo no podrán sustituir 
las emociones reales de estar físicamente en un lugar, independientemente de los posibles inconvenientes o peligros que tuviera el destino (Sussmann \& Vanhegan, 2000).

La innovación en sus plataformas, dispositivos y herramientas de producción de contenido permite que la realidad virtual evolucione desde una tecnología de nicho que se disfruta principalmente dentro de las comunidades de juegos al ámbito de las experiencias diarias (Tussyadiah et al., 2017). Las experiencias virtuales ayudan a preparar y motivar a los turistas para que visiten físicamente un destino, además de ser un apoyo como medio publicitario para incentivar y despertar interés en el usuario. Por lo que distintas organizaciones públicas y privadas, apuestan por la ejecución de proyectos tecnológicos que aporten con la misión de atraer al turismo (Haz et al., 2016). Esto debido a que aún es poco común observar estrategias visuales de difusión sobre lugares turísticos, lo típico es usar los medios de comunicación tradicionales como la radio, la televisión y la Internet. Lo cual se complica si se trata de un lugar no muy conocido y con pocos recursos para pagar grandes campañas publicitarias. De ahí que se busquen nuevos medios de difusión y que estén al alcance de las personas.

Por tal motivo, el objetivo del presente trabajo es diseñar y desarrollar un escenario virtual que contenga los principales atractivos turísticos del municipio de Tepeapulco, Hidalgo. Así como crear una aplicación para celular basada en realidad virtual que sirva para incentivar el turismo, ya que a corto plazo la Presidencia Municipal planea proponer a Tepeapulco como Pueblo Mágico ante la Secretaría de Turismo del país. Esto conlleva también tener un resguardo digital de los lugares, que a pesar del constante mantenimiento que se les da, con el paso del tiempo se han ido deteriorando. Con lo anterior se fomenta el uso de nuevas tecnologías en actividades que benefician directamente a la sociedad.

\section{Las TIC y el turismo mexicano}

El empleo de las TIC en el entorno relacionado al turismo dentro del territorio mexicano ha aumentado en los últimos años. Junto con la Internet, se han convertido en herramientas indispensables para generar que los turistas visiten los diferentes lugares que se promocionan, ya que les brindan información sin importar la región en donde estén y el momento en que la requieran (Berné et al., 2015). Asimismo, mediante páginas web, apps, redes sociales, revistas digitales, comercio electrónico, e incluso la realidad aumentada (superpone 
elementos virtuales sobre la visión de la realidad), las TIC han facilitado las transacciones comerciales en la industria al establecer contactos con socios comerciales, la distribución de productos y el suministro de información a los consumidores (Shanker, 2008).

De acuerdo con la Secretaria de Turismo [SECTUR] (2018), la llegada de turistas internacionales a México en 2018 fue de 41.4 millones, superior en 2 millones 156 mil turistas al observado en 2017 y equivalente a un crecimiento anual de 5.5\%, ubicando al país en el sexto sitio a nivel mundial por arribo de turistas internacionales. El ingreso de divisas por concepto de viajeros internacionales ascendió a 22 mil 510 millones de dólares, lo que representó un incremento de $5.5 \%$ respecto a 2017. Cabe señalar que los principales destinos turísticos del país son: Cancún, Riviera Maya, Los Cabos, Puerto Vallarta y Ciudad de México, quienes representan el $80 \%$ de los viajes de turistas extranjeros. Sin embargo, la llegada de turistas nacionales a cuartos de hotel en 2018 fue muy superior, alcanzando los 60 millones 875 mil turistas (73.6\% del total), mientras que 21 millones 850 mil fueron turistas internacionales (26.4\% del total). Según datos del Instituto Nacional de Estadística y Geografía [INEGI] (2018), en el año 2016 la actividad turística contribuyo con el 8.7\% del Producto Interno Bruto (PIB) del total del país. Las cifras anteriores se han logrado en gran parte gracias a que con la Internet y las nuevas tecnologías el turista puede planificar, reservar y pagar su viaje desde cualquier parte del mundo, incluso sin necesidad de intermediarios.

Dadas las cifras anteriores, es complicado que un turista internacional visite lugares poco conocidos, por lo que se debe buscar que el turista nacional sea quien visite primeramente dichos lugares. Por tal motivo, en el año 2001 la Secretaría de Turismo creó el programa Pueblos Mágicos en colaboración con diversas instancias gubernamentales y gobiernos estatales y municipales. El programa contribuye a revalorar a un conjunto de poblaciones del país que han sabido preservar la riqueza cultural e histórica que encierran, y que representan alternativas frescas para los visitantes (SECTUR, 2013). Además de que busca promover los encantos del país, haciendo hincapié en los atributos simbólicos, leyendas, historia, hechos trascendentes, cotidianeidad, magia, entre muchas otras particularidades, que emanan en sus diversas manifestaciones socioculturales. Hoy en día, la publicidad de los 121 Pueblos 
Mágicos existentes está basada, principalmente, en páginas web, revistas digitales y aplicaciones móviles, por lo que es sencillo encontrar información sobre ellos.

\section{Realidad virtual}

Según el Diccionario de la Real Academia Española [RAE] (2018), realidad virtual es la "representación de escenas o imágenes de objetos producida por un sistema informático, que da la sensación de su existencia real". El principal objetivo es emular mundos artificiales, que deben cumplir con la mayor cantidad de propiedades del mundo real o una física y lógica bien entendidas por el usuario. Con ello es posible generar en el espectador la sensación de inmersión y que se sienta parte de ese mundo (Heras \& Villareal, 2011). Varias tecnologías conspiran para crear esta ilusión, incluyendo: pantalla estereoscópica, hardware de seguimiento de movimiento, dispositivos de entrada y plataformas móviles (Parisi, 2015).

Existen dos tipos de realidad virtual: la realidad virtual inmersiva es aquella que se da en un ambiente 3D con el cual los usuarios pueden interactuar a través de cascos, guantes y otros accesorios para el cuerpo; la otra es la realidad virtual no inmersiva, en la que el usuario interactúa con el mundo virtual de manera más sencilla con la utilización de teclado y el ratón (Vince, 2004). Técnicamente hablando, la realidad virtual inmersiva es una interfaz humanomáquina avanzada que permite experimentar de manera multisensorial, una simulación computarizada de manera interactiva y en tiempo real. Consta de equipamientos, instalaciones, software, hardware y aplicaciones diseñadas para tal fin. En el proceso cognitivo asistido por esta herramienta, resaltan dos factores principales: el aspecto sensorial en la percepción del mundo virtual y las formas de interacción del usuario con él (Lucet y Espinosa, 2004). Son aplicaciones de realidad virtual inmersiva aquellas que se experimentan con varios de los sentidos, en especial la visión, la audición y el tacto. La calidad del sonido tridimensional contribuye mucho a la sensación de inmersión (Cruz et al., 2006).

Esta nueva tecnología permite a los investigadores definir de forma explícita y exhaustiva las señales sensoriales que transportan la información sobre el mundo virtual. En experimentos del mundo real, no es posible controlar o medir todas las señales sensoriales. La realidad virtual ofrece los medios para agregar o quitar señales sensoriales para probar la contribución de cada uno a un código neural y para construir un conjunto mínimo de 
estímulos necesarios para producir un comportamiento dado o un patrón de actividad neural (Minderer et al., 2016).

En un principio la realidad virtual fue usada en su mayoría para aplicaciones militares. Sin embargo, en los últimos años se han diversificado las áreas en las que se utiliza, destacando educación, medicina, ingeniería, entretenimiento e incluso manipulación remota de robots (Vince, 2004). Debido a que es un elemento atractivo y motivador, los mundos virtuales en 3D ofrecen oportunidades para que las empresas de mercadotecnia turísticas se enfoquen en mercados específicos al ofrecer un entorno innovador para que los visitantes potenciales exploren destinos turísticos (Huang et al., 2016). A medida que el uso de la realidad virtual aumenta, sus aplicaciones dentro del turismo también, destacando la planificación y la administración, el mercadeo, el entretenimiento, la educación, la accesibilidad y la preservación del patrimonio (Guttentag, 2010). A pesar de lo anterior, aún existe poca comprensión acerca de cómo comercializar estos servicios turísticos y del impacto económico generado en la industria. No obstante, se pueden mencionar algunas experiencias que evidencian los beneficios de la realidad virtual en el turismo:

- La cadena de hoteles Marriot comenzó a colocar lentes de realidad virtual en sus habitaciones, lo que permitió que sus huéspedes viajaran a diferentes lugares del mundo y de este modo planificaran su siguiente destino. El 51\% de las personas dijo estar interesado en viajar a uno de esos destinos (Isostopy, s.f.).

- La Universidad de Fachhochschule en Salzburgo (Austria), comparó el uso de un video promocional grabado en $360^{\circ}$ de la ciudad de Dubrovnik (Croacia) con material turístico convencional. La visualización inmersiva despertó hasta un $67 \%$ más el deseo de visitar la ciudad (Isostopy, s.f.).

- Empresas de tecnología han realizado videos $360^{\circ}$ de realidad virtual para que las personas conozcan lugares históricos que hoy en día son de difícil acceso, como la Acrópolis de Atenas o el Coliseo Romano; así como lugares imposibles de visitar, como la superficie lunar o el sistema solar (Editeca, 2018).

- En México se han realizado videos $360^{\circ}$ de realidad virtual para recorrer museos, como el Museo Frida Kahlo, el Museo del Templo Mayor, el Museo Nacional de Arte y el 
Museo del Palacio de Bellas Artes (Gatopardo, 2016); así como para publicitar zonas arqueológicas, como Chichen Itzá y Teotihuacan (Editeca, 2018). Esto ha aumentado su popularidad en redes sociales, ya que las personas pueden conocer el interior de estos lugares a pesar de su lejanía.

\section{Tepeapulco, Hidalgo}

Tepeapulco es una localidad mexicana, cabecera del municipio del mismo nombre, en el estado de Hidalgo. La palabra Tepeapulco significa "en el cerro grande" o "lugar donde baja agua del cerro" en náhuatl. Ubicado en una región denominada los llanos de Apan, lugar históricamente importante porque ahí se realizaron los primeros estudios sobre la lengua náhuatl. Sin mucha fama, el municipio cuenta con atractivos turísticos y culturales, entre los que destacan (Tepeapulco, 2016):

- Centro histórico: en 1824 se elevó a categoría de municipio Tepeapulco. El centro de la población es un lugar privilegiado que alberga un jardín principal con un kiosco, rodeado por casas antiguas.

- Exconvento de San Francisco de Asís: es el primer convento en el estado de Hidalgo cuyas paredes acogieron los primeros memoriales por Fray Bernardino de Sahagún y los sabios ancianos de Tepeapulco, construido entre 1527 a 1530 en honor a San Francisco de Asís.

- Acueducto y caja de agua: también conocido como la Diosa del Agua o Los Lavaderos, Construido de 1541 a 1545 y que a pesar de los años sigue vertiendo el preciado líquido por las bocas de los leones, acueducto de ingeniería hidráulica que recorre $27 \mathrm{~km}$ desde los manantiales de Alcantarillas, Apan.

- Casa de Hernán Cortes: residencia de Hernán Cortes, quien mando a construir una casa que al inicio ocupaba toda una manzana, se dice que cuando llegan los evangelizadores franciscanos se alojaron en este espacio e iniciaron la construcción de la iglesia y convento.

En la Figura 1 se muestran las imágenes de los lugares antes mencionados, los cuales fueron elegidos para el recorrido virtual debido a su popularidad y majestuosa historia. Cabe señalar que Tepeapulco es un lugar poco turístico en la región y en general en el estado. Esto de 
Olvera Mejía, Y.; Gea Pérez, M.; González Silva, M.

acuerdo con cifras que muestran que, durante las vacaciones de Semana Santa de 2018 en Hidalgo, aproximadamente 20,000 personas visitaron el Corredor de Haciendas (incluye a Tepeapulco), mientras que la afluencia en los Pueblos Mágicos fue de 545,609 personas, en Pachuca de 470,905 personas, y en el Corredor de los Balnearios de 2,232,368 personas (Benítez, 2018). A pesar de esta situación, se han desarrollado pocas estrategias publicitarias para difundir el lugar. Dichas estrategias se basan principalmente en trípticos y anuncios espectaculares distribuidos en los caminos que rodean la comunidad, así como reportajes televisivos de canales regionales y, algunas veces, nacionales. Ellas, sin embargo, no resultan novedosas ya que están dirigidas mayormente al público local que ya tiene conocimiento del sitio. De ahí la importancia de generar aplicaciones multimedia que, mediante Internet, lleguen a más personas en todo el país, al mismo tiempo que sean de su agrado.

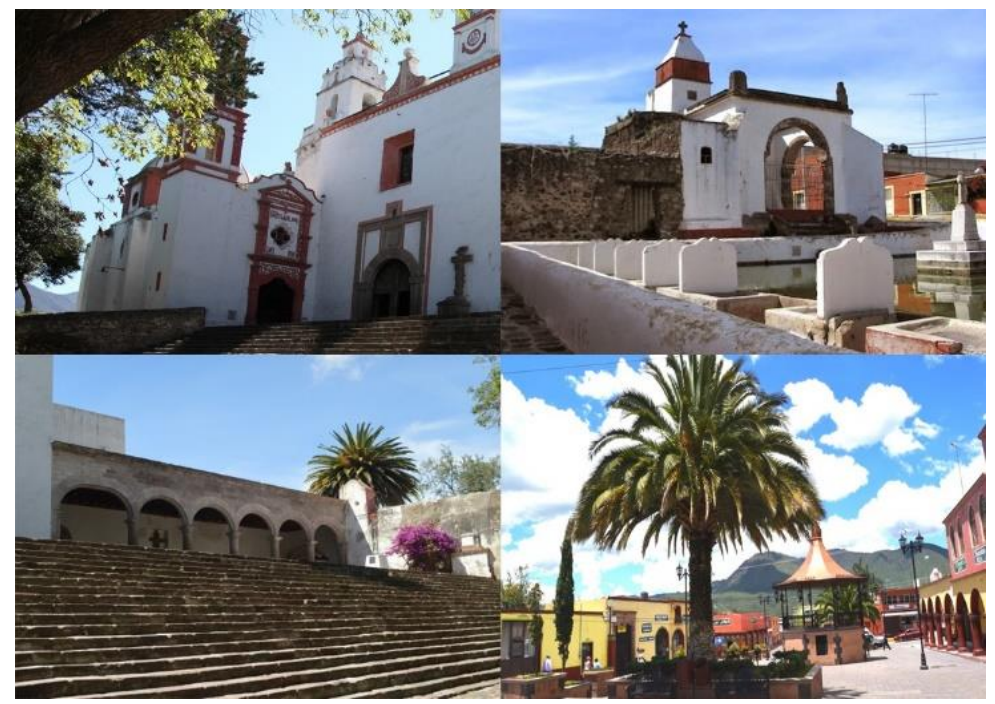

Figura 1. Lugares turísticos de Tepeapulco. 


\section{Escenario virtual de Tepeapulco}

Seleccionados los lugares a promocionar, la idea es desarrollar una aplicación de realidad virtual basada en ellos para potenciar el atractivo turístico del municipio. Para ello, se propone, primeramente, la creación de un escenario virtual hecho por computadora. Esto permite proyectar el producto final de una forma más real, dispuesta y atractiva, con el único objetivo de que el usuario se convierta en un sujeto activo, explorador de la información (Haz et al., 2016). De modo que en un futuro cercano considere visitar el municipio.

Lo primero es realizar todos los modelos 3D de edificios, arboles, monumentos y demás objetos existentes en el entorno. Al hablar de diseño 3D se refiere a la creación tridimensional de objetos, o a la creación de imágenes en 3D relacionadas con el mundo multimedia y la animación 3D. Los pasos básicos para lograr un objeto 3D son: modelado, mapeado UV, texturizado, iluminación y render.

$\mathrm{Al}$ iniciar el modelado, se debe definir una escala de una unidad por metro (1:1) en el sistema de medidas, así como reducir la cantidad de polígonos al máximo para hacer la malla de modelado más ligera, evitar desorden en las coordenadas y minimizar el tiempo de carga en las aplicaciones. También se obtienen las imágenes de referencia para los modelos, que son imágenes 2D de una o más vistas ortogonales de un objeto determinado, las cuales son insertadas como guía para modelar con mayor exactitud y precisión que modelarlo a simple vista. Una vez definido lo anterior se procede a realizar el modelo 3D de cada figura en el software Maya. Para ello, por lo general, se crea un cubo o cilindro en la pantalla y luego, utilizando diversas herramientas de modelado, se expanden gradualmente las diversas caras (polígonos) del cubo en cualquier forma básica que se requiera.

Después de realizar el modelo 3D, se obtienen sus mapas UV en imágenes coplanares, las cuales permiten su edición para darle color o textura. Aquí se verifica que cada plano contenga solo cuatro vértices, por lo que algunos se deben de unir sin dañar la posición inicial y la forma de la geometría. Con ello se procede a crear el mapa basado en la dirección de las rectas normales con respecto al objeto y sus caras. Una vez terminados los mapas, se editan en el software Photoshop para ponerles diferentes colores, materiales, texturas, rugosidad, etc., de acuerdo con cada objeto para posteriormente exportarlo a Maya otra vez. Lo siguiente 
es asignarles iluminación a los modelos 3D mediante luces de diversos tipos, como son: puntuales, direccionales, en área o volumen. El propósito de la iluminación es generar más realismo a los objetos (Olvera et al, 2017).

Finalmente, se efectúa el renderizado, que consiste en procesar el polígono, sombras, reflejos, iluminación, etc., para generar imágenes realistas, las cuales, tomadas desde diferentes ángulos, garantizan que los modelos 3D cumplen con los requerimientos. Para este proceso se utiliza el motor de render de Maya denominado Arnold, el cual analiza el comportamiento de la luz con respecto a los materiales o texturas, así como la forma en que rebota en la superficie. En la Figura 2 se presenta la comparación entre los lugares reales en la población y los generados por modelado 3D.

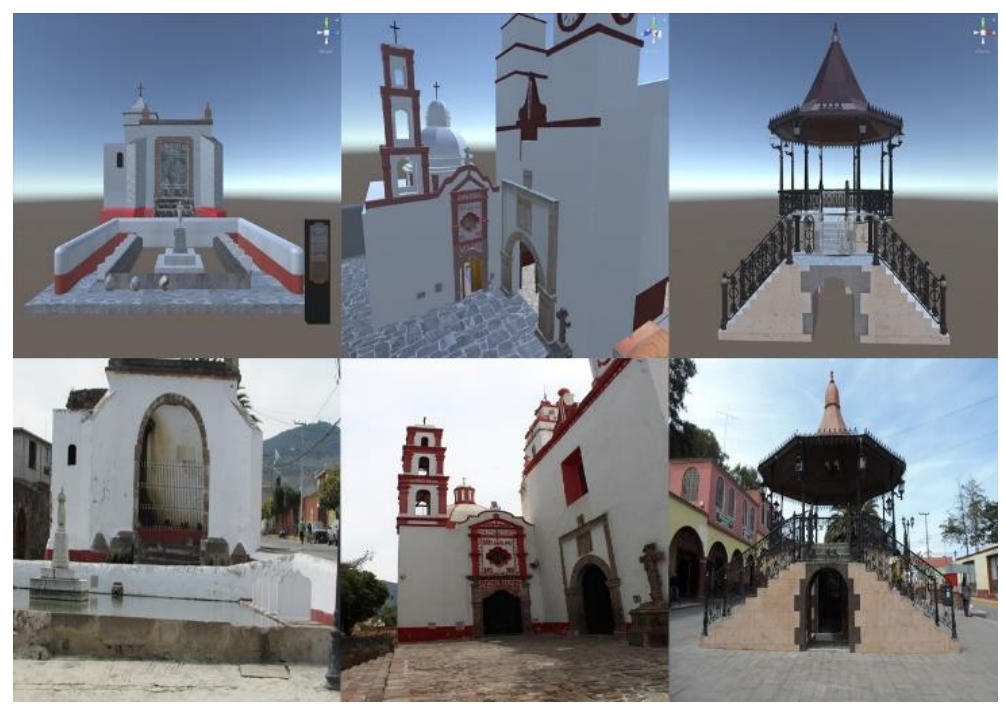

Figura 2. Comparación entre los lugares reales y sus modelos 3D.

De manera general, los métodos de digitalización que se tratan en este texto cumplen con las siguientes etapas: presentación de las necesidades, elección de las técnicas que deben aplicarse, adquisición de datos de campo, procesamiento de datos, control de calidad y entrega (Héno \& Chandelier, 2014). Una vez creados todos los modelos y objetos, se exportan al entorno virtual, el cual es elaborado en el software Unity, que proporciona las 
herramientas de desarrollo y creación de simuladores o escenarios virtuales (Olvera et al., 2016). En Unity se realiza todo el desarrollo de Tepeapulco y se colocan los objetos en la posición correcta de acuerdo con el plano del lugar. Ya que los lugares turísticos se encuentran alejados entre sí, se diseñó un entorno que incluyera todos los atractivos en una pequeña porción de espacio, lo cual facilita al usuario moverse entre los distintos atractivos en menos tiempo.

El primer paso es crear el terreno, el cual comienza como una malla plana, y, a través de varias funciones, es modelado y esculpido hasta obtener la geometría correcta. Una vez que se tiene el aspecto deseado, se pueden aplicar las diferentes texturas. Después, se colocan los modelos 3D importados. Es importante continuar con la escala usada en la creación de los modelos 3D, ya que la compatibilidad con el escenario depende de ello. Para cumplir con este punto, se utiliza la vista de usuario o maximizarlo a pantalla completa. Esto también permite ver la simulación en movimiento para comprobar su correcto funcionamiento. Al igual que con los modelos 3D, el entorno debe ser iluminado con la misma intensidad de luz, aunque puede variar un poco según las diferentes texturas del terreno. Finalmente, se agrega a la escena el cielo, las nubes, el agua, así como efectos de clima. La Figura 3 muestra imágenes del escenario virtual.

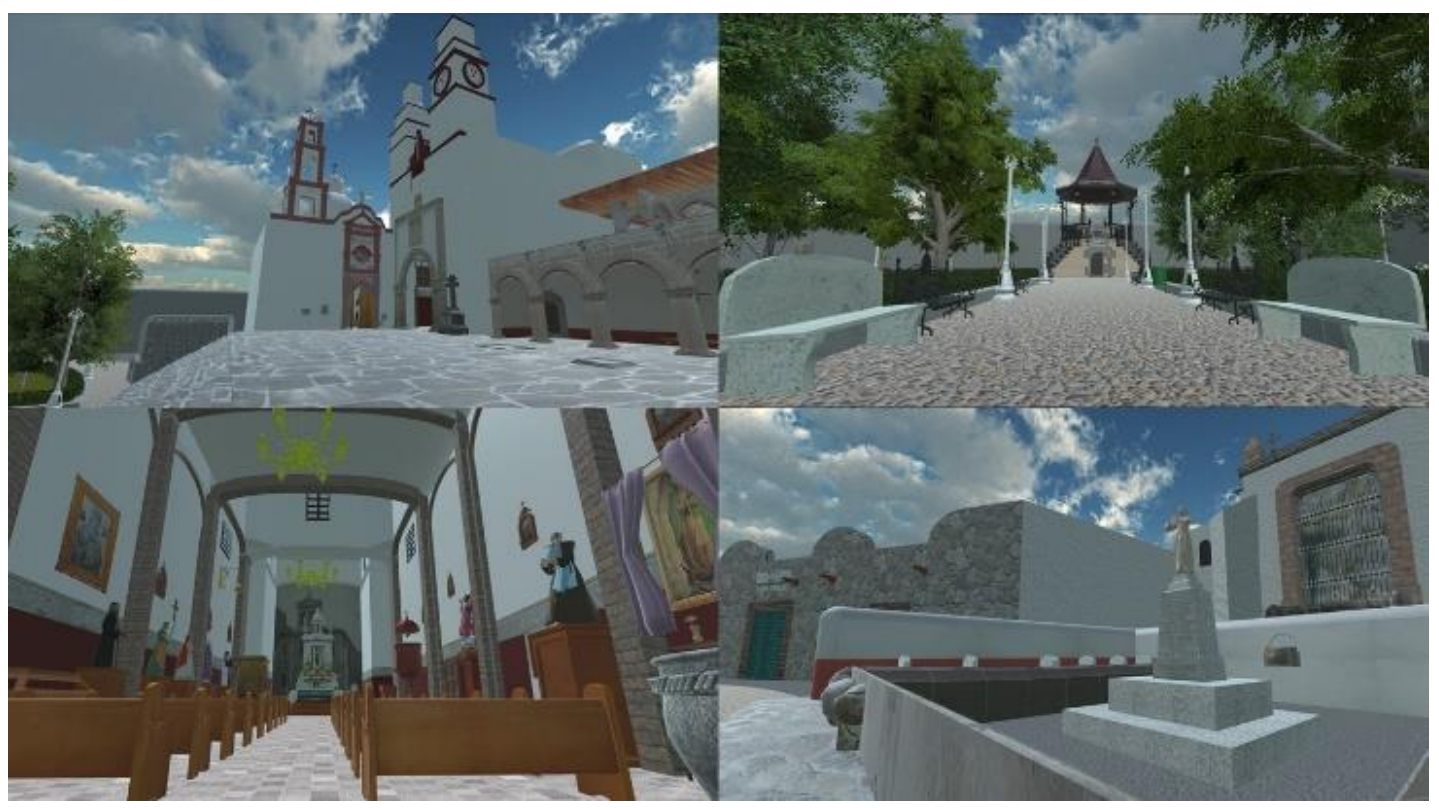

Figura 3. Escenario virtual con los atractivos turísticos. 
También en Unity se realiza la programación de objetos para que tengan capacidad de movimiento, como puertas y árboles. Se colocan colliders en todos los objetos para que la cámara no pueda traspasarlos y sea lo más real posible. La música de fondo y los sonidos para ciertos elementos son incluidos para darle más interactividad. Además, se configuran cuadros de texto con información de cada atractivo turístico para que se desplieguen al posicionarse frente a ellos. Los scripts de programación se realizan en lenguaje C\#.

\section{Aplicación de realidad virtual}

Una vez hecho el escenario virtual, se procede a realizar la aplicación en realidad virtual por medio de Google Cardboard, el cual funciona a partir de montar un teléfono inteligente con giroscopio y acelerómetro en una base de cartón plegable recortado y con dos lentes. El desarrollo de este proceso se resume a la necesidad en la aplicación de que la cámara se mueva por medio de un joystick, en el cual se programan una serie de scripts. Esto a raíz de que el plugin original solo contiene el script para convertirlo a realidad virtual, pero no proporciona el movimiento del personaje o cámara. Debido a esta necesidad se utiliza la cámara principal de Unity (Main Camera), adaptando los scripts y objetos para su movimiento. La estructura jerárquica de la cámara de realidad virtual es la siguiente: el objeto principal que se utiliza como "Padre" se le denomina VR_GENERAL, siendo este solo un objeto vacío que realiza la función de unión de los dos objetos "Hijos", llamados "Cardboard Main” y "Overlay Canvas". Los hijos a su vez contienen objetos y scripts, siendo el más importante dentro del funcionamiento “Cardboard Main”, en su estructura hay cinco objetos:

1. First Person Controller: Contiene scripts que hacen la función de movimiento del personaje y los movimientos $360^{\circ}$ de la cámara, permitiendo la rotación de la cámara.

2. Main Camera: Contiene un par de objetos denominados "MC_Left" y "MC_Right", que son los dos ojos, dividiendo la pantalla para lograr el efecto de realidad virtual.

3. Walk Pointer: Es el objeto que sirve como apoyo para hacer que la cámara se mueva por medio del joystick.

4. Graphics: Es el objeto de capsula que sirve para conectar todo, simulando ser el personaje. 
5. Stereo render: Contiene dos elementos que proporcionan el render del proyecto, dando la apariencia final del mismo llamándose "Pre-Render" y "Post-Render".

El otro "Hijo" de VR_GENERAL es "Overlay Canvas", el cual solo contiene el FPS que funge como la pantalla que permite configurar la parte de realidad virtual, siendo este un plugin de Google Cardboard. Con los cambios anteriores es posible realizar la aplicación de realidad virtual, así como mover la cámara dentro del escenario por medio de un joystick.

\section{Resultados y discusión}

Como último recurso se realiza el testeo para encontrar y resolver los problemas que existan en la puesta en marcha de la aplicación, así como para verificar diversos aspectos, como son: fiabilidad, eficiencia, portabilidad, escalabilidad, mantenibilidad, compatibilidad, usabilidad y capacidad. Hecho lo anterior se procede a realizar la versión Beta de la aplicación, lo cual significa que está prácticamente terminada y funcionando como se observa en la Figura 4.

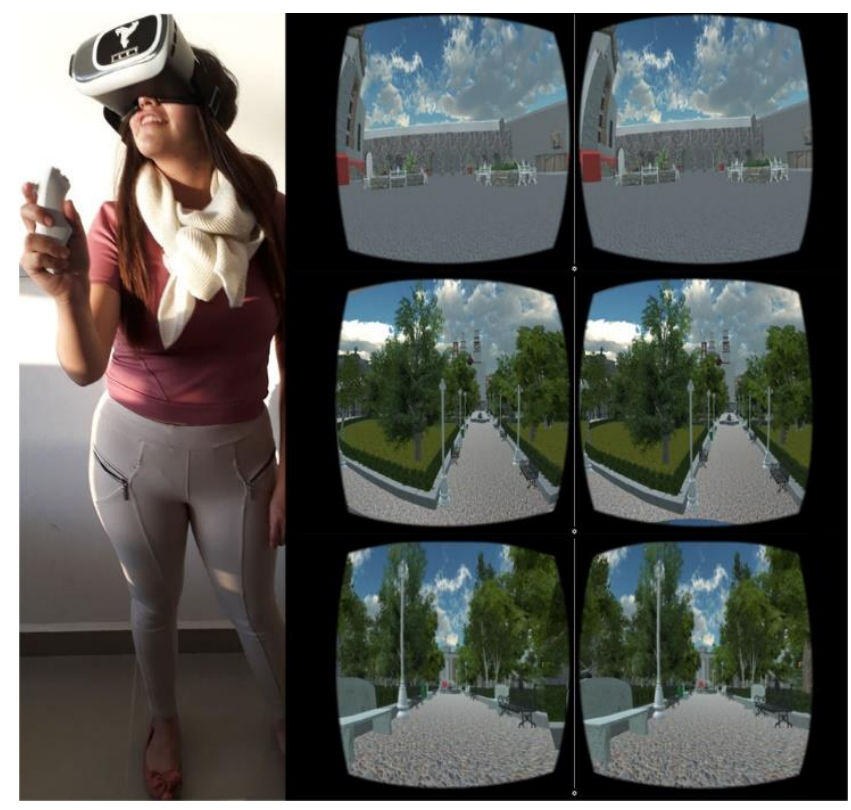

Figura 4. Aplicación de realidad virtual. 
Para comprobar la eficacia de la aplicación, se probó en turistas que arribaban al centro de Tepeapulco en un fin de semana. Para ello, todo el conjunto de la aplicación se instaló a un lado del kiosco. Es un lugar con afluencia de turistas, ya que normalmente hay personas del municipio que proporcionan información sobre lugares a visitar, restaurantes, hoteles, tours, etc. De todas las personas a las que se les presentó y probaron la aplicación, 100 en total, 60 eran del estado de Hidalgo y 40 de otros estados del país. La mayoría conocía el tipo de atractivos que tiene el municipio, ya que en Internet habían investigado un poco sobre el pueblo. Sin embargo, una parte no conocía todos los lugares turísticos ni la historia que conlleva cada uno, por lo que no tenía contemplado visitarlo.

Los resultados fueron positivos, principalmente en los jóvenes, ya que aceptaron con agrado e interés el uso de nuevas tecnologías para promover el municipio, además lograron manejar con mayor rapidez el joystick y los movimientos de cámara. Mientras que los adultos tuvieron ciertas dificultades para dominar la realidad virtual, aunque reconocieron que es una idea innovadora y atractiva. De manera general, la gente considero visitar alguno de los lugares que no conocía, ya que se interesó por su historia. Consideraron importante el uso de nuevos medios para promocionar turísticamente lugares poco conocidos, ya que en la actualidad hay más apertura a los medios de comunicación y difusión. También pidieron informes para adquirir no solo la aplicación, sino información histórica acerca del municipio y de los lugares turísticos que ahí se encuentran.

Adicionalmente, se aplicó un breve y sencillo cuestionario de 5 preguntas a las personas que probaron la aplicación de realidad virtual para conocer su opinión sobre el uso de esta tecnología y su aplicación en el turismo. De acuerdo con los resultados, mostrados en la Tabla 1, se comprobó que la aplicación cumple con su objetivo de incentivar a la gente a visitarlo. Es evidente que cada una de las personas tiene diferentes gustos e intereses de acuerdo con su edad, experiencias de vida, nivel de estudios, etc., pero todas son consumidoras de las tecnologías digitales. Por lo tanto, la principal utilidad de la aplicación es describir y analizar el conjunto de características del lugar para mostrar al turista, a través de habilidades tales como: percepción, atención, comprensión, pensamiento, representación de conocimiento, memoria y lenguaje (Bruning et al., 2005). 
Tabla 1. Cuestionario a usuarios de la app.

\begin{tabular}{lcc}
\hline Pregunta & Sí (\%) & No (\%) \\
\hline ¿Alguna vez has experimentado una experiencia de inmersión 3D? & 59 & 41 \\
¿Disfrutaste el recorrido por medio de la realidad virtual? & 95 & 5 \\
¿Crees que esta app ayuda a atraer el turismo a la zona? & 88 & 12 \\
¿Descargarías la app en tu celular? & 79 & 21 \\
¿Consideras que el uso de la tecnología mejora el desarrollo de la & 100 & 0 \\
sociedad? & & \\
\hline
\end{tabular}

¿Qué te gustó más de la aplicación?

El escenario en tres dimensiones y poder moverme en él.

La información histórica que proporciona de los lugares.

La similitud con los atractivos reales.

El uso de tecnología en la comunidad.

Sugerencias:

Insertar animaciones para hacer más interactivo el recorrido.

Poner más información sobre los lugares turísticos.

Incluir música de acuerdo con el lugar.

Hablar sobre la historia de tepeapulco de manera general.

Fuente: Elaboración propia.

El propósito de este trabajo no es realizar un alegato a favor de las animaciones y mundos virtuales, sino adentrar en su conocimiento, ya que el desarrollo de esta tecnología abre múltiples posibilidades en el ámbito turístico. En los últimos años el uso de estos medios ha ido en aumento, llegando a abarcar prácticamente a toda la sociedad, máxime a los niños y adolescentes. De ahí la importancia de entender lo valioso e importante que es la propuesta de introducir escenarios virtuales, realidad virtual e incluso realidad aumentada en la promoción turística de diversas localidades. En el mercado ya existen aplicaciones que fundamentan esta propuesta, por ejemplo: Orbulus VR para visitar una gran cantidad de lugares naturales, Arts and Culture para conocer lugares patrimoniales y aprender su valor 
histórico, Sites in VR para visitar monumentos y joyas arquitectónicas de todo el mundo, Within VR para conocer las ciudades más famosas, entre muchas otras (Baboonlab, s.f.).

La principal diferencia de la aplicación propuesta de Tepeapulco con las ya existentes es el escenario, ya que las aplicaciones existentes contienen videos de acción real (live-action), mientras que la aplicación descrita se basa en imágenes generadas por computadora (CGI). Esto genera un valor adicional debido a que los gráficos de computadora 3D son más llamativos para la mayoría de las personas, por lo que pueden recordar cierta información por más tiempo. Asimismo, se promociona un lugar poco (o nada) conocido en comparación con las otras aplicaciones que promocionan lugares por todos conocidos y sobre todo atractivos en todos los sentidos, esto último garantiza la descarga de las aplicaciones y genera conversación en redes sociales. Sin embargo, lo que se pretende a mediano plazo es crear una plataforma que contenga recorridos virtuales de lugares no muy conocidos ni visitados, principalmente del estado de Hidalgo, con la finalidad de incentivar el turismo regional y nacional, así como potenciar el desarrollo social y tecnológico en la zona.

Pueden existir partidarios y detractores de estos medios, sin embargo, no se puede ignorar los cambios que suceden en la sociedad y el impacto que generan en la forma en que se proporciona la publicidad, con promotores usando las TIC como estrategia turística. Dejando claro que, como ya se ha mencionado, no hay nada como estar físicamente en el lugar y observar sus maravillas.

\section{Conclusiones}

El diseño, desarrollo e implementación de una aplicación de realidad virtual para dar a conocer turísticamente los lugares del Municipio de Tepeapulco en el Estado de Hidalgo es descrito a profundidad. La finalidad es que las personas por medio de un celular realicen un recorrido virtual por los atractivos turísticos para conocer su historia, y con ello incentivar su visita. Al mismo tiempo, tiene como propósito conservar digitalmente cada uno de estos lugares ya que con el paso del tiempo se han ido deteriorando poco a poco a pesar del constante mantenimiento que se les da. Se plantean actividades como storyboard, modelado 3D, mapeado UV, texturizado, iluminación y render para realizar primeramente el escenario 
virtual; y adecuación de cámara, instalación de plugins, creación de scripts, emparentado de cámara al personaje y la creación del APK (Paquete de Aplicación de Android) para el desarrollo de la aplicación de realidad virtual. El proceso es muy tardado y complejo, ya que se cuidan los detalles al momento de modelar los objetos 3D y realizar los escenarios virtuales, asimismo deben ser archivos ligeros de tamaño para que la aplicación cargue rápido y no ocupe demasiado espacio en su instalación. Al probar la aplicación con turistas que estaban en la localidad de Tepeapulco, la mayoría coincidió en que es una forma interesante y agradable de promocionar un destino turístico, considerando acudir a los lugares mencionados. Por lo que la aplicación cumple con su objetivo de ser un nuevo medio de difusión turística. Además de ayudar a que, en un futuro no muy lejano, el municipio de Tepeapulco se convierta en Pueblo Mágico.

\section{Referencias}

BABOONLAB (s.f.). Las mejores aplicaciones gratis de realidad virtual para iOS y Android. Recuperado el 15 de marzo de 2019 de: http://www.baboonlab.com/blog/ noticias-de-marketing-inmobiliario-y-tecnologia-1/post/las-mejores-aplicaciónesgratis-de-realidad-virtual-para-ios-y-android-30

BENÍTEZ E. (25 de abril, 2018). Más de tres millones de turistas visitaron Hidalgo en Semana Santa. Criterio. Recuperado el 15 de marzo de 2019 de: https://www. criteriohidalgo.com/destacado/mas-de-tres-millones-de-turistas-visitaron-hidalgo-en -semana-santa

BERNÉ, C., GARCÍA-GONZÁLEZ, M., GARCÍA-UCEDA, M. E., \& MÚGICA, J. M. (2015). The effect of ICT on relationship enhancement and performance in tourism channels. Tourism Management, 48, 188-198.

BRUNING, R. H., BUENO AlvAREZ, J. A., NORBY, M. M., RONNING, R. R., SÁNCHEZ BAIDES, J., \& SCHRAW, G. J. (2005). Psicología cognitiva y de la instrucción. Pearson Educación. 
BURDEA GRIGORE, C., \& COIFFET, P. (1994). Virtual reality technology. London: Wiley-Interscience.

CHAMORRO, R. (2008). Una revolución en el turismo gracias a las TIC. Bit, 170, 30-33.

CRUZ, M., MORALES, A., \& AYALA RUIZ, A. (2006) Diseño de productos asistidos por realidad virtual inmersiva. Ingeniería mecánica, tecnología y desarrollo. 2(3), 93100.

EDITECA (2018). Realidad virtual aplicada al turismo. Recuperado el 15 de marzo de 2019 de: https://editeca.com/realidad-virtual-turismo/

GATOPARDO (2016). Arte en la realidad virtual. Recuperado el 15 de marzo de 2019 de: https:/gatopardo.com/estilo-de-vida/museos-realidad-virtual/

GHISI, L., \& MACEDO, S. (2006). Turismo virtual on-line: um estudo em sites brasileiros que divulgam o turismo. In III CONVIBRA, Congresso Virtual Brasileiro de Administração, São Paulo.

GUTTENTAG, D. A. (2010). Virtual reality: Applications and implications for tourism. Tourism Management, 31(5), 637-651. doi.org/10.1016/j.tourman.2009. 07.003 .

HAZ, L., CRUZ, P., \& SÁNCHEZ J. (2016) La realidad virtual como herramienta tecnológica para fomentar el turismo en la península de Santa Elena. 3C Tecnología. 5(3), 53-67. doi:10.17993/3ctecno.2016.v5n3e19.53-67.

HÉNO, R. \& CHANDELIER, L. (2014). 3D modeling of buildings: outstanding sites. US: Iste.

HERAS, L., \& VILLAREAL, J. (2011). La realidad virtual en los nuevos paradigmas de la ciencia de datos. Revista Digital Universitaria. 12(9).

HUANG, Y. C., BACKMAN, K. F., BACKMAN, S. J., \& CHANG, L. L. (2016). Exploring the implications of virtual reality technology in tourism marketing: An integrated 
research framework. International Journal of Tourism Research, 18(2), 116-128. doi.org/10.1002/jtr.2038.

INEGI (2018). Estadística a propósito del día mundial del turismo (27 de septiembre). Recuperado el 15 de marzo de 2019 de: http://www.beta.inegi.org.mx/contenidos/ saladeprensa/aproposito/2018/turismo2018_Nal.pdf

ISOSTOPY (s.f.). ¿Qué puede aportar la realidad virtual al turismo? Recuperado el 15 de marzo de 2019 de: https://www.isostopy.com/realidad-virtual-turismo/

LUCET L., \& ESPINOSA J. (2004). IXTLI, un espacio para el aprendizaje y descubrimiento asistidos por la realidad virtual, Mensaje Bioquímico. 28.

MARTínEZ, F. J. P. (2011). Presente y Futuro de la Tecnología de la Realidad Virtual. Creatividad y sociedad, (16), 1-39.

MINDERER, M., HARVEY, C. D., DONATO, F., \& MOSER, E. I. (2016). Virtual reality explored. Nature. 533(7603), 324. doi:10.1038/nature17899.

MOLINA, S. (2003). O pós-turismo. São Paulo: Aleph, 27.

OLVERA Y., GEA, M., \& BARRÓN, J. (2016). Creación de Videojuego Didáctico sobre Matemáticas para Estudiantes de Primaria, Revista de Sistemas Computacionales y TIC's. 2(5), 9-16.

OLVERA, Y., VARGAS, J., \& ECHENIQUE, L. (2017). Uso de Realidad Aumentada para Promocionar los Pueblos Mágicos de Hidalgo mediante el Modelado Digital en 3D de sus atractivos Turísticos. Exploratoris Observatorio de la Realidad Global. 2(6), $15-22$.

PARISI, T. (2015). Learning virtual reality: Developing immersive experiences and applications for desktop, web, and mobile. O'Reilly Media, Inc.

PRIDEAUX, B. (2005). Cyber-tourism: a new form of tourism experience. Tourism Recreation Research, 30(3), 5-6. doi:10.1080/02508281.2005.11081481. 
Olvera Mejía, Y.; Gea Pérez, M.; González Silva, M.

REALIDAD VIRTUAL (2018). En Diccionario de la Lengua Española de la Real Academia Española. Recuperado el 15 de marzo de 2019 de: https://dle.rae.es/?id=VH7cofQ.

SECTUR (2013). Programa Pueblos Mágicos de México. Reglas de Operación. Distrito Federal: Secretaría de Turismo.

SECTUR (2018). Resultados de la actividad turística 2018. Recuperado el 15 de marzo de 2019 de: http://www.datatur.sectur.gob.mx/RAT/RAT-2018-12(ES).pdf

SHANKER, D. (2008). ICT and Tourism: Challenges and Opportunities, Proceedings of the International Conference on "Tourism in India-Challenges Ahead", Indian Institute of Management Kozhikode; pp. 50-58.

SUSSMANN, S., \& VANHEGAN, H. (2000). Virtual reality and the tourism product substitution or complement?. ECIS, Proceedings, Surrey. 117, 1-8.

TEPEAPULCO (2016). Catálogo de prestadores de servicios turísticos. Recuperado el 15 de marzo de 2019 de: http://www.tepeapulco.gob.mx/Tepeapulco.html

TUSSYADIAH, I. P., WANG, D., JUNG, T. H., \& TOM DIECK, M. C. (2018). Virtual reality, presence, and attitude change: Empirical evidence from tourism. Tourism Management, 66, 140-154. doi:10.1016/j.tourman.2017.12.003.

VINCE, J. (2004). Introduction to virtual reality. Springer Science \& Business Media. 